\title{
La representación de las cariátides en el Vitruvio: fortuna iconográfica y arquitectónica
}

\section{The Representation of Caryatids in Vitruvius: Icon- ographic and Architectural Fortune}

\author{
ELENA MERINO GÓMEZ \\ Universidad Nebrija. Madrid. Campus Dehesa de la Villa \\ emerino@nebrija.es \\ JUAN ANTONIO RODRÍGUEZ FERNÁNDEZ \\ Universidad Nebrija. Madrid. Campus Dehesa de la Villa \\ jrodrigf@nebrija.es
}

Recibido: 06/09/2015

Aceptado: 28/09/2015

\section{Resumen}

El objeto de este trabajo es mostrar la fortuna icónica del modelo de las cariátides, desde que estas son por primera vez representadas para el Vitruvio por Fra Giocondo da Verona. Su decisión y modo de ilustración condiciona la producción iconográfica posterior, que opera interacciones constantes con las versiones sucesivas de la tratadística vitruviana. Las variaciones del modelo están determinadas por conocimientos arquitectónicos directos, hallazgos, vestigios arqueológicos e interpretaciones textuales, todo ello aderezado, en muchos casos, por el ingenio creativo de sus autores. Las distintas soluciones gráficas al tipo de las cariátides a lo largo del siglo XVI, se reflejarán en las representaciones que ilustran las traducciones a otras lenguas europeas en períodos posteriores. En virtud de la permanencia en el tiempo de la obra de Vitruvio y de su difusión geográfica es posible definir rasgos de evolución y características formales peculiares dependiendo del contexto de producción. 


\title{
Palabras clave
}

Cariátides, Vitruvio, ilustración, representación gráfica, tratados de arquitectura.

\begin{abstract}
The object of this work is to show the iconic fortune of the caryatides model, since they were represented for the first time within the Vitruvius by Fra Giocondo da Verona. His decision and mode of illustration determines the posterior iconographic production which operates permanent interactions with subsequent versions of treatises on Vitruve. The variations over the model are conditioned by direct architectural knowledge, discoveries, archaeological remains and textual interpretations, all of them, embellished by the creative genius of their authors. The different graphical solutions provided for the caryatides archetype throughout the $X V^{\text {th }}$ century will influence the representations which illustrate the translations into some other European languages in later periods. By virtue of the immanence in time of vitruvian work and of its geographical diffusion, it is possible to define evolution features and particular formal characteristics depending on diverse production contexts.
\end{abstract}

\section{Keywords}

Caryatides, Vitruvius, illustration, graphical representation, treatises on architecture.

Referencia normalizada: MERINO GÓMEZ, ELENA - RODRÍGUEZ FERNÁNDEZ, JUAN ANTONIO (2015): “La representación de las cariátides en el Vitruvio: fortuna iconográfica y arquitectónica". Arte y Ciudad. Revista de Investigación, no 8 (octubre), págs. 163-180. Madrid. Grupo de Investigación Arte, Arquitectura y Comunicación en la Ciudad Contemporánea, Universidad Complutense de Madrid.

Sumario: 1.- El "hallazgo" del Vitruvio. 2.- Las cariátides en las primeras ilustraciones. 3.- La edición de Daniele Barbaro y Andrea Palladio. 4.- Recogiendo los modelos iconográficos italianos: la ilustración de las cariátides en Francia. 5.- Conclusiones. 


\section{Introducción.}

Cuando Poggio Bracciolini reclama en 1416 haber recuperado el texto de De Architectura de Vitruvio, ilustres personajes anteriores al Quattrocento ya habían tenido acceso a manuscritos de la obra vitruviana. Desde su redacción en el último cuarto del siglo I a.C., el texto no llegó jamás a perderse, a pesar de lo que el pretendido hallazgo de Bracciolini pudiera dar a entender. Existen noticias que permiten trazar la transmisión textual desde las tempranas referencias en las obras de Plinio el Viejo y de Frontino, pasando por la tradición debida a los scriptoria monásticos en la Alta Edad Media, hasta los ejemplares anotados que pertenecieron a Boccaccio y Petrarca. La magna labor en favor de la tradición clásica que le debemos a la Schola Palatina propicia la reproducción y difusión de los textos en las distintas instituciones monásticas sobre las que esta influyó y explican la presencia de una copia en el monasterio de Saint Gall, donde Bracciolini pretendió haber hallado el manuscrito presuntamente olvidado para la posteridad.

El texto "redescubierto" en el Quattrocento carecía de las ilustraciones a las que, sin embargo, una redacción intrincada y plagada de incorrecciones gramaticales hacía continua referencia, contribuyendo a incrementar la oscuridad del significado pretendido por Vitruvio. La editio princeps tiene lugar en 1486, a cargo de Giovanni Sulpizio da Veroli, dedicado a la interpretación de gramáticas y textos clásicos, quien publica el texto junto con el De aquaeductu de Frontino, cuyo manuscrito había sido asimismo recuperado para el humanismo por el propio Poggio Bracciolini. Sulpizio (1486: 1) se lamenta en su edición de la ausencia de figuras y aconseja a los impresores la previsión de espacio en los márgenes "marginibus spatia" para que autores más documentados que él añadan comentarios e iluminen un texto que, a la sazón, presentaba pasajes de todo punto incomprensibles.

La edición que publica Giovanni Giocondo da Verona en 1511 supone la recuperación definitiva del texto al servicio de la arquitectura. La depuración filológica a la que Fra Giocondo somete el texto y que, por primera vez, permite la publicación de un todo coherente y comprensible, será tan trascendental para la historiografía de la arquitectura como la inserción de 136 imágenes que influirán de forma decisiva en toda la iluminación textual subsecuente, tanto en la selección de los motivos como en la morfología de ciertos modelos 
arquitectónicos (Ciapponi, 1984: 86). Fra Giocondo (1511) proclama que su edición del texto vitruviano se concibe para que, a partir de su publicación, tal como reza su título, pueda ser leído y comprendido: “[...] cum figuris et tabula ut iam legi et intelligi possit". Confluyen en Giocondo las facetas de filólogo y arquitecto, constituyendo su doble formación el sólido cimiento que favorece el prestigio y la consideración de su edición como un documento incontestable de referencia en toda la historiografía posterior.

\section{Las cariátides en las primeras ilustraciones.}

La hermosa invención de Vitruvio para imbuir al arquitecto la necesidad de ser una persona culta refiere, a modo de ejemplo, un apócrifo argumento histórico en virtud del cual se explica la presencia de mujeres esculpidas sosteniendo el peso de algunos edificios públicos. Según Vitruvio, el arquitecto deberá ser capaz de satisfacer la curiosidad de quienes pregunten la razón de tal motivo arquitectónico y habrá de relatar el castigo infligido a las mujeres de Caria por haber conspirado sus conciudadanos contra los griegos en auxilio del enemigo persa (Vitruvio, 1997: 27). No existe en el pasaje remisión explícita a ilustración alguna ${ }^{1}$, sin embargo, será esta la primera de cuantas aparezcan en la edición ilustrada por Giocondo. La anécdota, relatada solo a título de ejemplo, y por tanto en la periferia de los temas principales de los Diez Libros, ilustra por sí sola la conveniencia de "que el arquitecto sea una persona culta y conozca la literatura para fortalecer la memoria con sus explicaciones" (Vitruvio, 1997: 26). Sin embargo, lo pintoresco del asunto unido al probable conocimiento que Giocondo tenía de algún modelo real, se presta a su plasmación como figura fundamental adjunta al texto (Giocondo, 1511: 2r). Tal decisión motivará su presencia en la mayor parte de las ediciones ilustradas que secundarán la publicación de la pionera de Fra Giocondo de Verona.

Cuenta Vasari que Fra Giocondo "stette in Roma nella sua giovanezza molti ãni, e dãdo alla cognitione delle cose antique, cio è non solo alle

${ }^{1}$ Vitruvio remite en varias ocasiones, al final de cada libro, a las figuras que aclaran lo expresado en el texto. No será este el caso de las cariátides. Sirva como ejemplo de la remisión verbal a las figuras el siguiente fragmento: Puesto que hemos ofrecido una breve explicación, con el fin de que todo se comprenda sin grandes dificultades, me ha parecido bien plasmar en el último libro las dos figuras de los vientos, lo que los griegos llaman schemata. (Vitruvio, 1997: 48). 
fabriche" y el propio Poliziano dice de él que es "peritissimo in tutte le antiquità" (Vasari, 1568: 245).

En consecuencia, resulta posible suponer que su interés arqueológico lo llevó a conocer modelos de cariátides copiados profusamente por los romanos directamente del modelo del Erecteion durante los siglos I y II d.C. (Stevenson, 2001: 65) y extendidos desde entonces al repertorio iconográfico de arquitecturas de carácter tanto público como privado con muy distinta función: religiosa, votiva, funeraria, o meramente decorativa.

Si existe consenso acerca de lo arbitrario del relato vitruviano sobre las cariátides (Homolle, 1917; Vickers, 1985; Plommer, 1979), no es tan unánime la opinión relativa a la simbología que se les atribuye. De lo servil a lo sacro, pasando por lo protector o lo propagandístico, lo cierto es que la gestualidad facial representada por Giocondo (Fig. 1) difiere un tanto de la serenidad impertérrita del modelo canónico que constituyen las doncellas del Erecteion. Parece debatirse esta primera representación cinquecentesca entre los modelos arqueológicos probablemente conocidos por Giocondo, de rostro siempre impenetrable, y el relato de punición vitruviano, que confiere, al menos a la primera de las tres representadas, un semblante aspaventado y grave, coherente con la "poena peccati caryatiu”" (Giocondo, 1511: 1v). La situada en el centro esboza una suerte de sonrisa, mientas que la del extremo derecho es la que más se aproxima, careciendo de expresión concreta, a los arquetipos del Erecteion.

Resulta más que plausible que Fra Giocondo dibujara de memoria las figuras de las cariátides. A diferencia de su forma de operar en otros pasajes del texto, en los que las representaciones superan a la propia descripción merced al conocimiento técnico de Giocondo acerca de algunos artefactos (Ciapponi, 1984: 85), el dibujo de las cariátides aparece poco detallado y adolece de ausencia de cientificidad. El hecho de representar un esquema inusual de tres figuras -los más frecuentes constan de frentes de dos cariátides flanqueando una entrada o de cuatro, constituyendo asimismo un esquema simétrico para centrar un acceso- constataría que Fra Giocondo se limitó a ilustrar el ejemplo con un afán meramente descriptivo, lejos de sus esfuerzos de presentar figuras explicativas y aclaratorias destinadas a iluminar otros pasajes ciertamente oscuros de De Architectura. La representación del atuendo tampoco responde a los cánones de la vestimenta ática, con los típicos patrones prácticamente 
exentos de costuras que se esculpen tradicionalmente en las cariátides, tanto en las de origen griego como en sus versiones romanas, lo que reforzaría la hipótesis de que no responden a ningún original concreto y son solo producto de la traslación verbatim del texto al lenguaje gráfico.

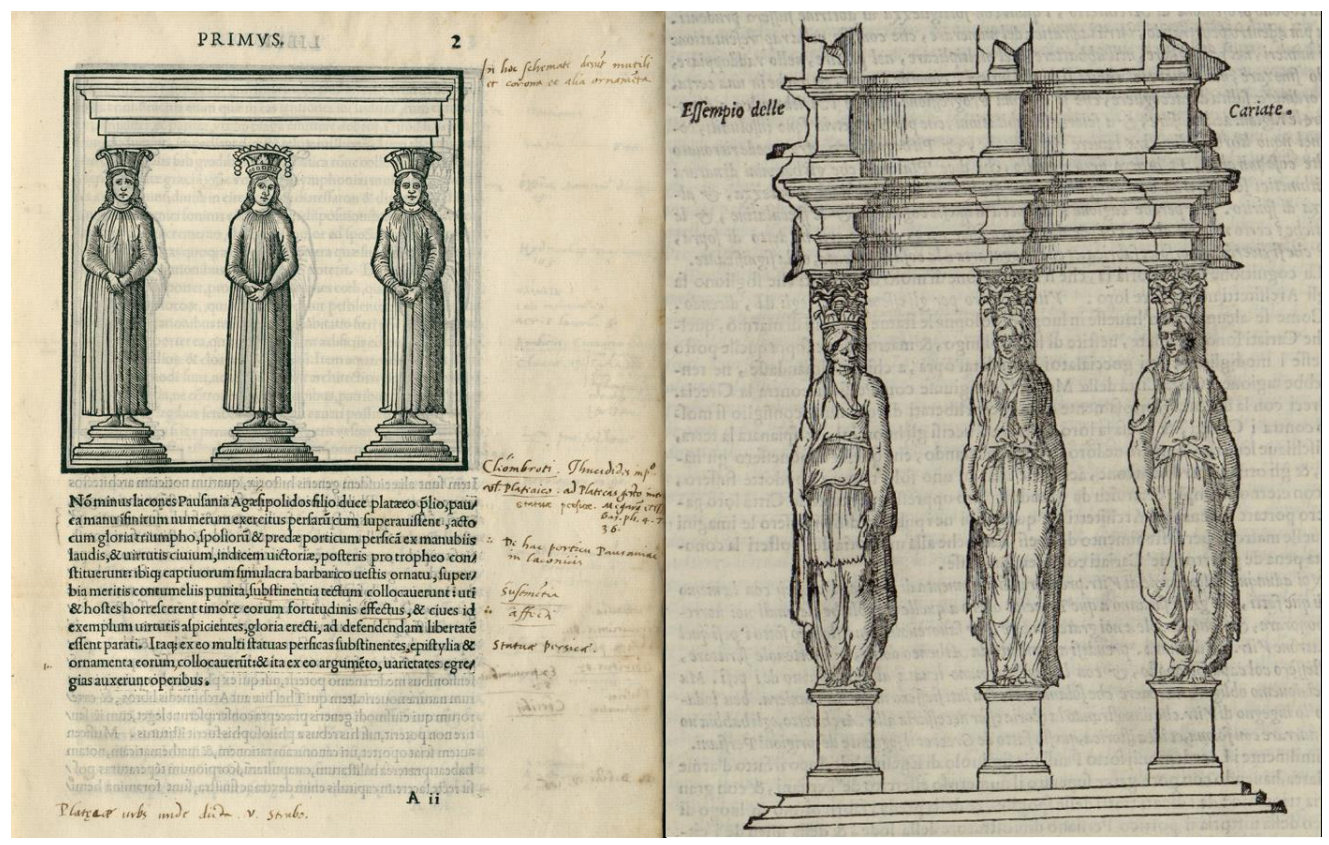

Fig. 1. Imagen con los esquemas de tres cariátides que aparecen en la primera edición ilustrada de Fra Giocondo (1511: 2r) y con la repetición de la misma disposición de la edición de Barbaro y Palladio (1556: 24).

Independientemente del carácter acientífico de la representación de Fra Giocondo, resulta incontestable que la decisión de ilustrar la anécdota moralizante de Vitruvio determina que el pasaje aparezca recurrentemente ilustrado en las ediciones de sus epígonos. Su inmediato sucesor, Cesare Cesariano, publicará diez años después el texto depurado y corregido de Fra Gicondo traducido por primera vez a una lengua romance (Cesariano, 1521). La obra en toscano de Cesariano, con notables ilustraciones que revelan su condición de pintor ${ }^{2}$, ofre-

2 Aunque Vasari (1986: 578) se referirá a él como reputato buono geometra e buono architettore. 
ce una representación de las cariátides (Fig. 2) canónica solo en cuanto al número de figuras, pues son cuatro las que aparecen en el frente. La representación de Cesariano da crédito a lo referido, presentando las cariátides en pose convulsa, ciertamente afectada por la carga de la estructura, ayudándose con las manos a sostener el entablamento. La pesada cubierta que gravita sobre las imágenes brinda al pintor el pretexto para trazar los gestos manieristas que conmueven los rostros de las doncellas, cuyo atuendo también se aleja de los cánones de la Antigüedad y corresponde, en este caso, a los modelos aristocráticos del Renacimiento italiano.

Fig. 2. Representación de las cariátides en la edición de Cesare Cesariano (1521: 6r).

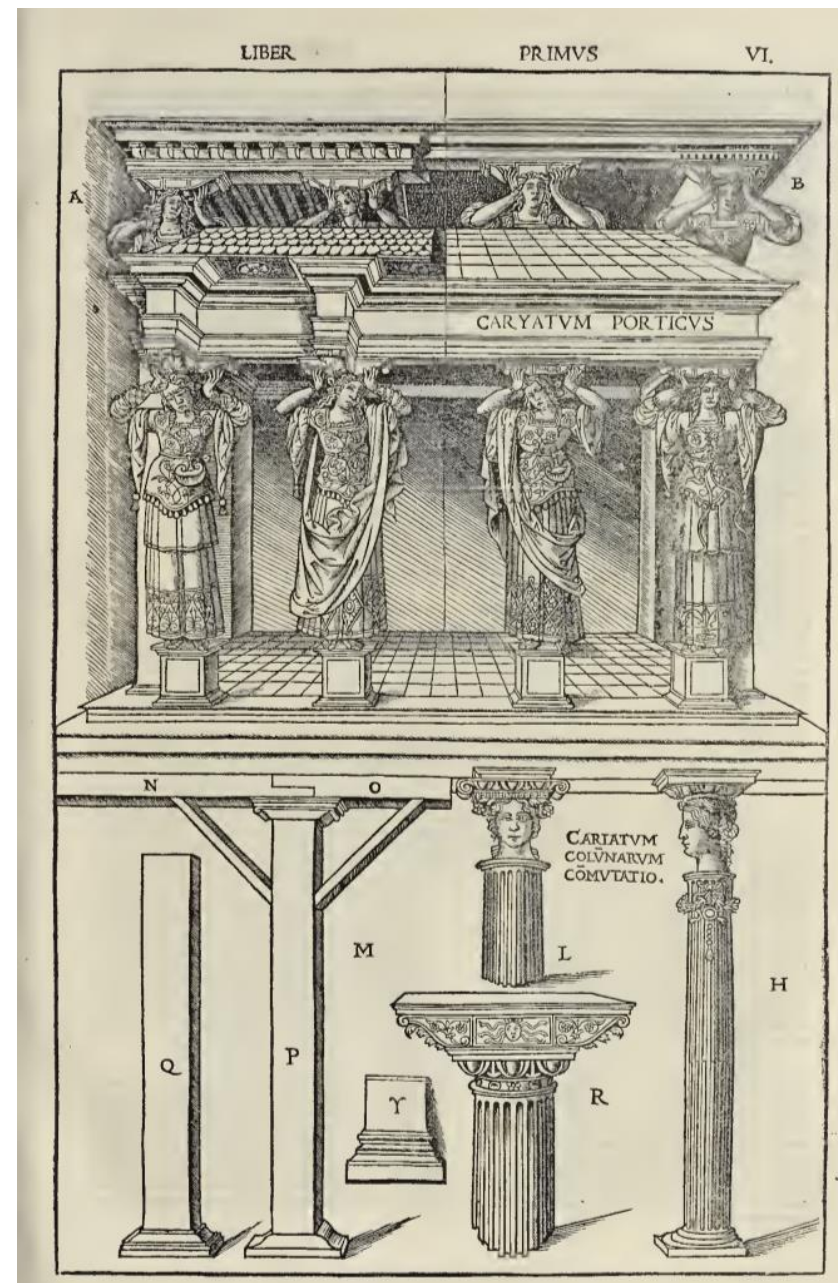




\section{ELENA MERINO GÓMEZ - JUAN ANTONIO RODRÍGUEZ FERNÁNDEZ}

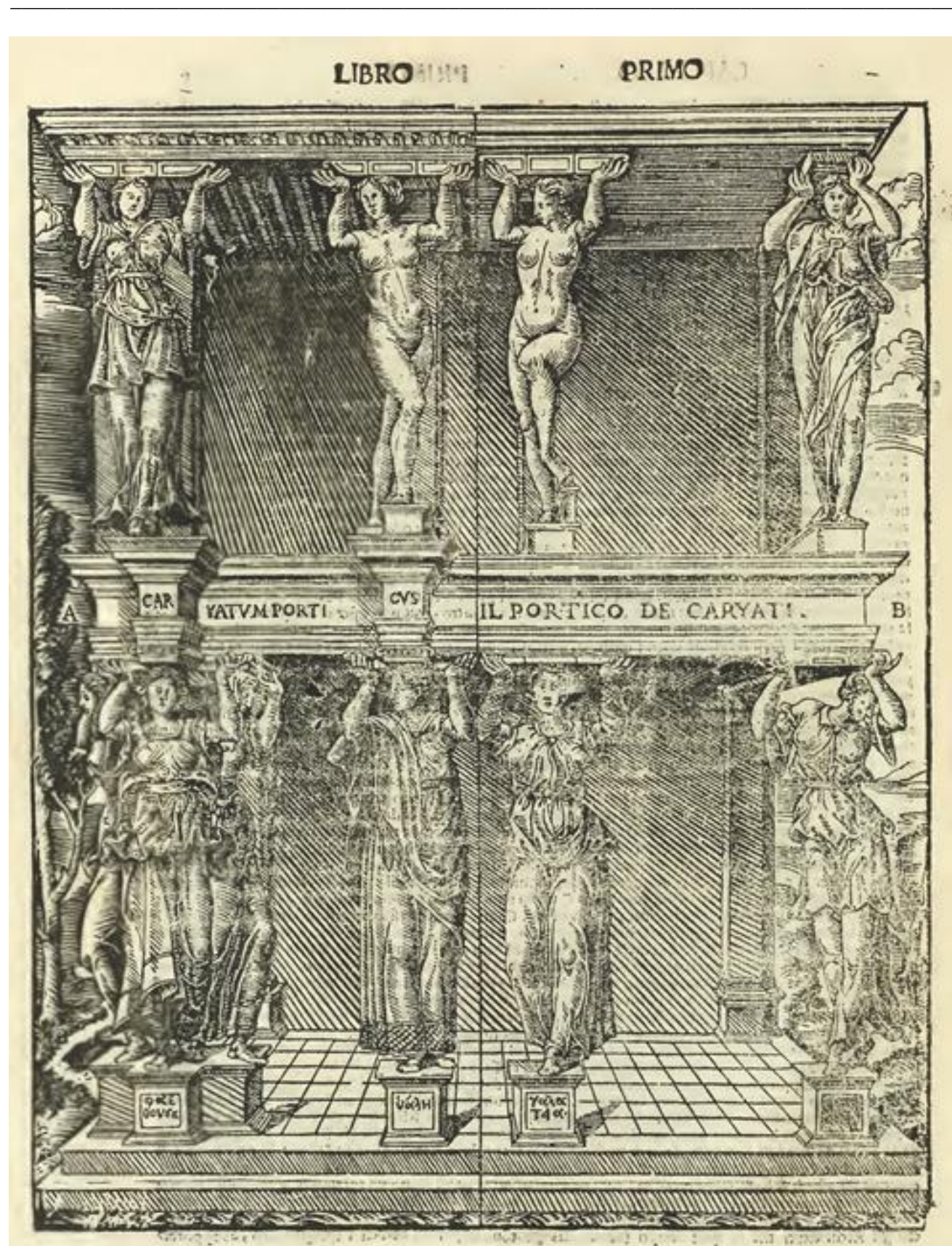

Fig. 3. Representación de las cariátides en la edición de Giovanni Battista Caporali (1536: 8v). 
Siguiendo la estela manierista marcada por Cesariano, Giovanni Battista Caporali presenta una versión más próxima al Barroco (Caporali, 1536: 8v). Con las figuras de las cariátides aún más contortas y rompiendo la simetría de los modelos anteriores, Caporali recrea un pórtico con un frente aparentemente tetrástilo (Fig. 3) que, en realidad, contiene en el extremo izquierdo un conjunto de tres cariátides: una que mira al frente y otras dos a sus espaldas, constituyendo con las otras tres cariátides del cuerpo inferior, un nutrido e inusual grupo de seis. Presenta asimismo una disposición peculiar del alzado consistente en una especie de logia, esta sí, con solo cuatro figuras, de las que osa desnudar a las dos centrales, manteniendo sin embargo el atuendo típico de las figuras femeninas de la Antigüedad, tanto en las dos que flanquean el grupo superior, como en las seis del cuerpo inferior. Si a Cesariano lo delataba su formación de pintor, a Caporali su expresivo grupo de figuras lo lleva a conformar un conjunto de difícil equilibrio arquitectónico, escogiendo una pictórica serpentinata para el extremo inferior derecho, uno de los puntos más exigentes desde el punto de vista estructural. En las anotaciones que Giovanni Masselli hace al Vasari indica que Caporali "ebbe piu fama come architetto che come pittore" (Masselli, 1832: 427), con lo que podemos concluir que su representación no pasa de ser un mero ejercicio efectista que relega sus conocimientos arquitectónicos a un segundo plano en aras de lograr una más que atractiva composición del grupo de las cariátides.

\section{La edición de Daniele Barbaro y Andrea Palladio.}

Difícilmente habría de repetirse en el contexto de la tratadística la conjunción única de erudición filológica y saber arquitectónico que se dio en la figura de Fra Giocondo da Verona. Cesariano y Caporali destacaron en sus facetas pragmáticas y prestaron notables ilustraciones a un texto vitruviano que en pocas décadas se había distorsionado y corrompido.

El humanista Daniele Barbaro se propone recuperar para la tratadística la magna obra vitruviana, tarea que le exigirá cuidar por igual la fidelidad a la tradición filológica y la calidad de su iluminación. La pretensión de Barbaro de emplazar la obra de Vitruvio al alcance de arquitectos no necesariamente versados en lenguas clásicas, para que pudieran incorporar el tratado a su práctica cotidiana, lo lleva a acometer una aventura editorial para la que hubo 
de recurrir al extenso conocimiento en arquitectura de la Antigüedad y a las dotes de dibujante que adornaban a Andrea Palladio.

Circulaban en ese momento por Italia y Europa versiones traducidas a distintas lenguas ${ }^{3}$ y con dispar grado de corrupción de una obra que, no solo era objeto de exégesis y controversia de eruditos, sino que se había erigido en pocas décadas en obra inexcusable de referencia en el quehacer arquitectónico, ya fuera por emulación de sus preceptos, por su interpretación o por oposición a los mismos. El resultado de la colaboración entre Barbaro y Palladio se publica en Venecia en 1556 a cargo del editor Francesco Marcolini da Forli (Barbaro; Palladio, 1556).

La edición que publica Francesco Marcolini en Venecia en 1556 es ilustrada en gran parte por Andrea Palladio. Refiere Barbaro que para iluminar su texto "ne i disegni delle figure importante io ho usato le opere di M. Andrea Palladio Vicentino" (Barbaro; Palladio, 1556: 46), de lo que se traduce que no todos los dibujos de la publicación son del arquitecto patavino. Sí parecen serlo los que nos ocupan en este trabajo según Cellauro (1998: 58), que refiere asimismo la adopción del modelo trazado por Fra Giocondo para la selección de motivos de ilustración. Es harto probable que el humanista Tolomei hubiera intercambiado pareceres con Barbaro acerca de la conveniencia de actualizar el Vitruvio mejorando la labor del fraile veronés. Remite Cellauro a la carta que Claudio Tolomei dirige al Conte Agostino de Landi sugiriéndole que es preciso actualizar las ilustraciones del Vitruvio:

Da questo mossi costoro hanno animo rinovar tutte le figure, disegnadole con piv bella grazia, e finezza che sarà possibile, emendando qvelle dove havesse errato Giocondo (Tolomei, 1547: 82).

No solo los documentos escritos avalan la aceptación de la edición de Giocondo como referencia figurativa. La propuesta palladiana de la disposición anómala del pórtico con tres cariátides remite inevitablemente al modelo repre-

${ }^{3}$ En Italia, además de las comentadas traducciones al toscano de Cesariano (1521) y Caporali (1536), se había difundido la de Francesco Lucio Durantino en 1424 (con la representación de las cariátides correspondiente a la edición de Fra Giocondo); en Europa, en el momento de la primera versión del Vitruvio de Barbaro y Palladio, circulaba la traducción al francés de Jean Martin (1547) y al alemán de Walter Hermann Ryff (1548). 
sentado en la primera edición ilustrada del Vitruvio (Fig. 1). Resulta obvio que Palladio corrige el atuendo anacrónico y esquemático de Giocondo y dota a sus figuras de un movimiento grácil, procurando comunicación visual entre ellas. El conjunto, más armonioso que su precursor, no aporta más información acerca del tipo arquitectónico y nada hay tampoco en él que nos remita a ningún modelo real conocido en el Renacimiento. Apunta Cellauro (1998: 69) que posiblemente el único motivo gráfico conocido por Palladio era una estampa de Marcantonio Raimondi, a la que el patavino habría modificado la transición al entablamento, transformándola de jónica en corintia. Observamos, sin embargo, mayores concomitancias, salvando las distancias impuestas por el atuendo simplificado y la tosquedad del trazo del veronés, con las formas dibujadas por Giocondo. La proporción de los poloi de la primera ilustración alienta la relectura corintia por parte de Palladio, contribuyendo al afán general de estilización que preside su labor ilustradora en mucha mayor medida que la disposición apaisada de la solución jónica de Raimondi.

\section{Recogiendo los modelos iconográficos italianos: la ilustración de las cariá- tides en Francia.}

La primera edición traducida al francés, anterior a la ilustrada por Palladio, es concebida con propósitos similares. Si Barbaro promueve la edición de un texto que auxilie al arquitecto en su labor cotidiana, Jean Goujon había a su vez observado la necesidad de renovación e introducción de términos vernáculos en una Francia que, a mediados del XVI, estaba importando modos arquitectónicos de Italia. Se revela entonces la importancia de producir un léxico que permitiera nombrar la nueva realidad constructiva y será Jean Martin, familiarizado con la lexicografía arquitectónica merced a su colaboración con Serlio, el responsable de traducir el texto latino al francés (Martin; Goujon, 1547).

Como le sucederá poco tiempo después a Barbaro, Martin debe recurrir a préstamos ilustres para iluminar su edición. Así, aparecen en ella dibujos de Giocondo, Cesariano y del propio Serlio, que Martin decide completar con las magníficas figuras ejecutadas ex profeso para su publicación por el insigne escultor y arquitecto Jean Goujon. Entre sus más admirables obras se cuenta la Tribuna de las Cariátides en el Louvre, encargada, según consta en contrato, el 5 de septiembre de 1550, y que Goujon debió de tener concluida hacia 1551 
(Réveil; Sulpis; Audot, 1869: 28). El dato resulta crucial en tanto en cuanto sería admisible la búsqueda de relaciones existentes entre las cariátides con las que ilustró el texto de Martin y las que tan solo tres años después habría de diseñar para el Louvre. No obstante, lo más probable es que, en este caso, el modelo escogido por Goujon para su representación sea la estampa de Marcantonio Raimondi a la que aludíamos en el apartado dedicado a Palladio. Las similitudes en el atuendo, prácticamente idéntico, el trenzado o el soporte jónico, por citar las más destacadas, determinan que el referente de Goujon fue la estampa de Raimondi. Si ampliamos la comparación al pórtico de los persas, resulta más que evidente cómo Goujon adopta incluso las mismas soluciones para el entablamento que soportan unos y otras (Fig. 4). La diferencia más remarcable estriba en la posición de los brazos, más próximo en Raimondi a la pose de la cariátide que posiblemente fue su modelo real (Cheney, 2006: 80) y que hoy se encuentra en el Museo Vaticano de Braccio Nuovo, mientras que en Goujon las figuras unen sus brazos en un gesto que recuerda lejanamente a la versión del veronés Giocondo.

Basta un somero acercamiento a la imagen de la Tribuna de las Cariátides en el Louvre para observar que, a pesar de la proximidad en el tiempo, el modelo adoptado por Goujon para su obra maestra es ajeno a la ilustración que presentó para el Vitruvio de Martin. Tal vez, como afirma Pérouse (2007:57), el modelo que vemos hoy en realidad no corresponde a un grupo de cariátides, pues no existe en el contrato mención al término "cariátide", en una época en la que está ampliamente difundido, sin embargo todo apunta a que, formalmente, las cariátides del Louvre representan una interpretación libre del modelo del Erecteion, compartiendo con él detalles como la simetría del contrapposto o permitiéndose Goujon lúdicamente emular la ausencia de brazos del objeto arqueológico.

A pesar de la belleza de las imágenes aportadas por Goujon al texto de Martin, la labor ilustradora no fue suficiente para desentrañar los pasajes más oscuros de un texto vitruviano al que Martin se ciñe con extremo rigor latinista en detrimento de la claridad de interpretación. Achacará Perrault ciento veinte años después el poco éxito de la edición anterior al hecho de que trabajaran en ella dos personas que conocían bien su disciplina, pero no aquella con la que interactuaban: 
Il y a six vingt ans que deux hommes sçavans, l'un dans les belles Lettres, l'autre en Architecture [...] entreprirent ce mesme Ouvrage auquel ils s'appliquerent conjointement \& avec beacoup de soin: Mais le peu de succés que leur travail a eu, fait bien connoitre que pur venir à bout de cette entreprise, il faut que la connoissance des Lettres, \& celle de 1'Architecture soien jointes en une mesme personne, \& en un degré qui soit au dessus du commun (Perrault, 1673: 23).
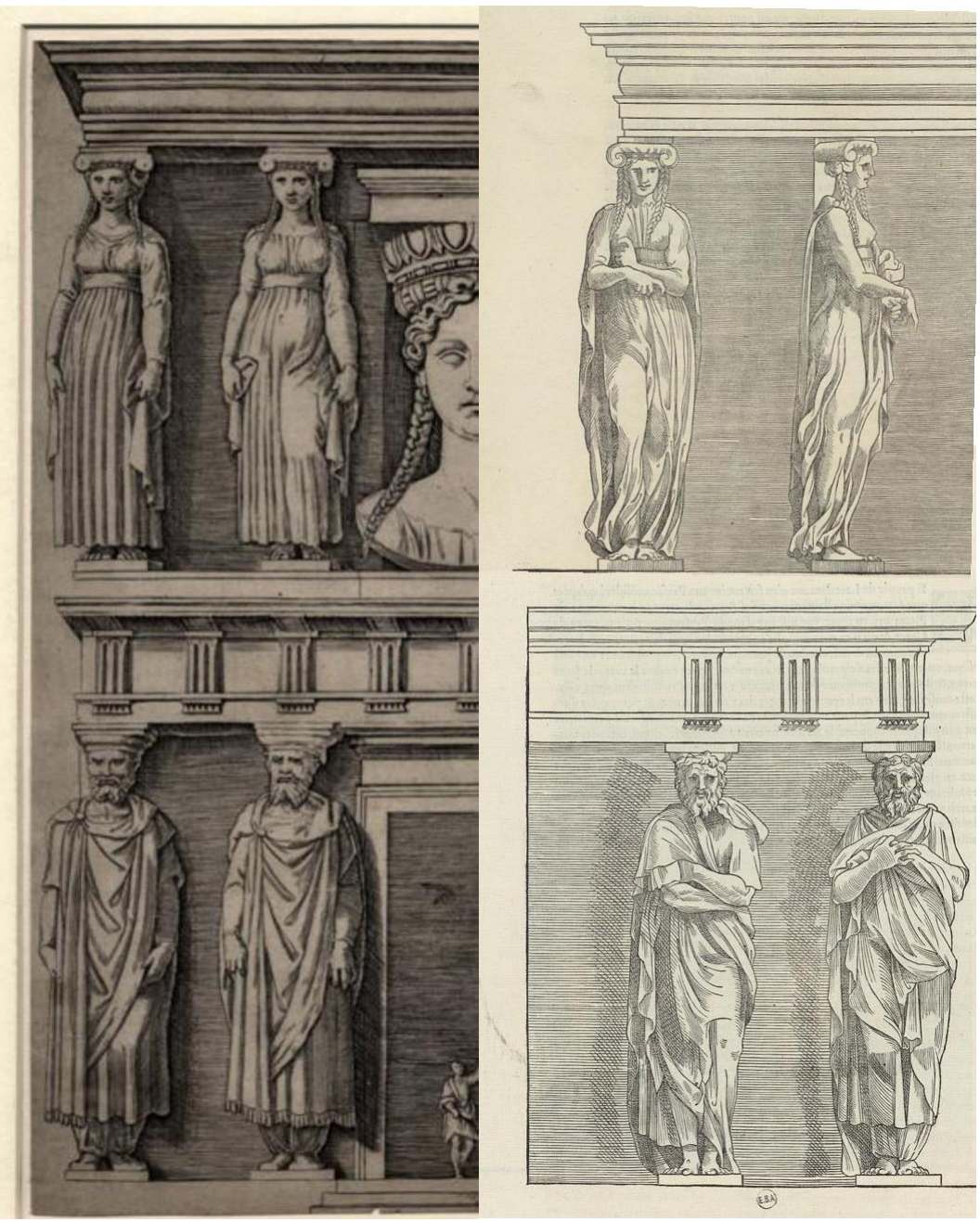

Fig. 4. Comparación de las cariátides y los persas presentes en la estampa de Marcantonio Raimondi (a la izquierda) y las representadas por Jean Goujon (a la derecha) para la versión francesa de Jean Martin (1547: 2v, 3v). 


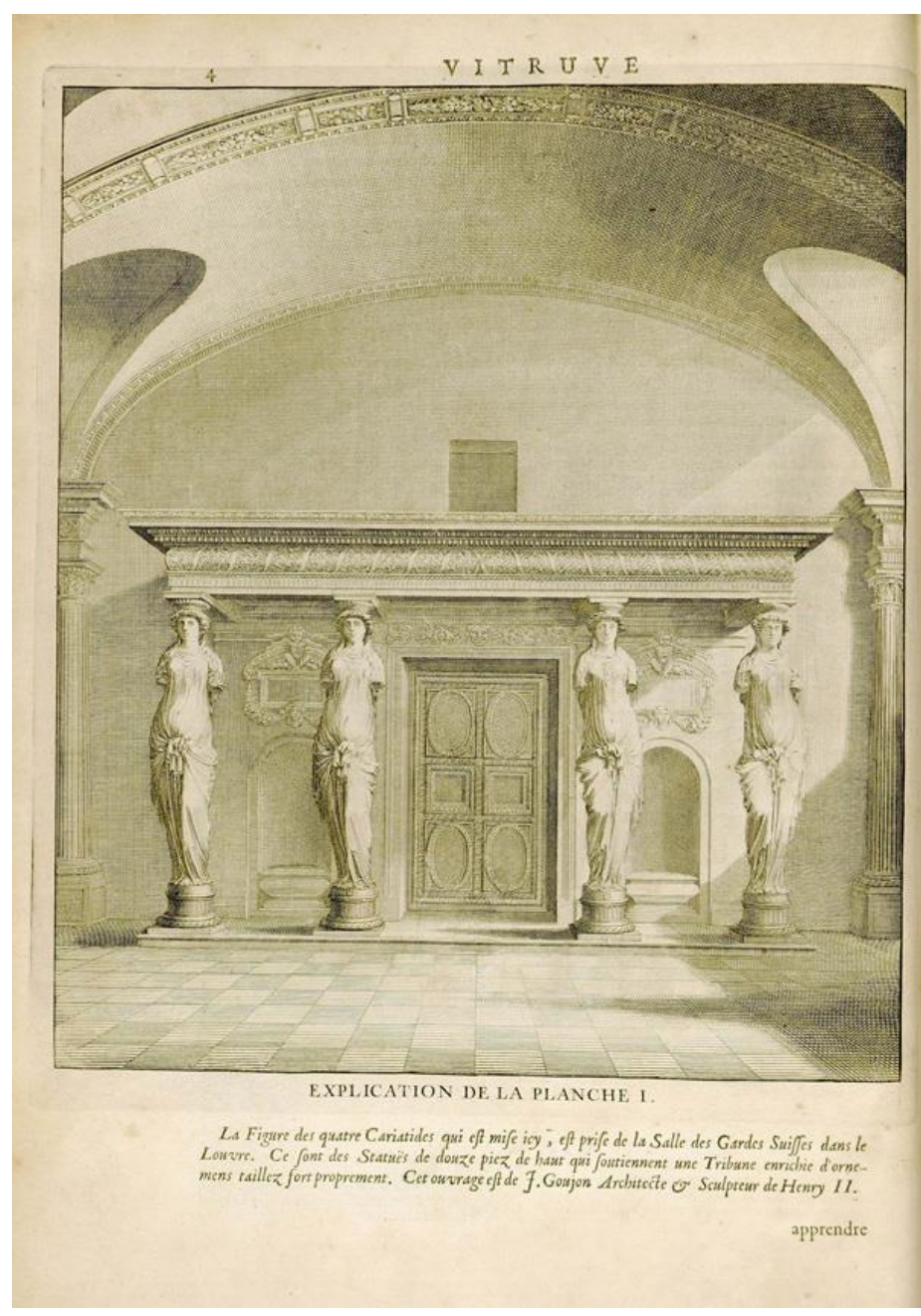

Fig. 5. Ilustración del pasaje vitruviano de las cariátides mediante el ejemplo construido de la Tribuna de las Cariátides del Louvre (1551) que aparece en la edición de Calude Perrault (1673: 5).

Sin embargo, el trabajo de Perrault, concebido para asentar los fundamentos de la arquitectura francesa con un principio válido de autoridad "en attendant que les sompteux edifices que S. M. fait construire en France, soient en état de servir eux-mesmes de modele à la posterité" (Perrault, 1673: 20), también se sirve de grabados ajenos para explicar unas páginas que, en los albores de la Ilustración, debían aparecer inexcusablemente iluminadas.

A pesar de la intención de Perrault de que el texto que publicaba diera sus frutos, a la espera de que los edificios franceses alcanzaran el grado de con- 
vertirse en modelos para la posteridad, lo cierto es que la figura adoptada para acompañar el texto de las cariátides corresponde a un fiel grabado de la tribuna del Louvre de Goujon (Fig. 5), ejecutada hacía más de un siglo y que, como otros tantos grabados de su edición, remite al edificio del que se enorgullecía y que habría de darle al galeno fama perpetua ${ }^{4}$.

Glosa Perrault a pie de imagen la obra de Goujon en elogiosos términos:

La figure des quatre Cariatides qui est mise icy, est prise de la Salle de Gardes Suisses dans le Louvre. Ce sont des Statues de douze piez de haut, qui soutiennent une Tribune enrichie d'ornemens taillez fort proprement. Cet excellent ouvrage est de J. Goujon Architecte \& Sculpteur de Henry II (Perrault, 1673: 5).

Indudablemente, la decisión de insertar en su ambiciosa edición citas gráficas de obras relevantes de la arquitectura francesa eleva de facto su rango y lo parangona con el resto de modelos de la Antigüedad presentes en la publicación. Queda así superada en los modelos gráficos su aparente intención de permanecer "en attendant" de ese futuro posible en el que la arquitectura francesa, gracias a su puesta al día del tratado de Vitruvio, fuera digna de ser equiparada a los modelos suntuosos de la Antigüedad.

\section{Conclusiones.}

Desde la primera representación de las cariátides que ofrece Fra Giocondo, el tipo aparece invariablemente inaugurando la secuencia de ilustraciones de gran parte de las versiones iluminadas de la obra de Vitruvio que suceden a la del fraile veronés. A pesar de la inmediatez que habría significado recurrir al modelo concreto del Erecteion al que alude el pasaje moralizante de Vitruvio, los principales ilustradores de su obra prefieren, emulando a Giocondo, ofrecer modelos de su invención sin aparentes referentes reales, cuando no reproducir sin más los aparecidos en versiones anteriores. El propio Andrea Palladio, conocedor directo de la arquitectura y los modelos escultóricos de la Antigüedad, se inspira sin embargo en el grabado primitivo de Fra Giocondo.

\footnotetext{
${ }^{4}$ Aparecen asimismo en el texto autocitas gráficas como l'Observatoire de Paris, del que fue autor, cuyas plantas, alzados y secciones acompañan el Capítulo II del Libro I. (Perrault, 1673: 13, 15).
} 
Jean Goujon, arquitecto, escultor y uno de los más excelsos ilustradores de la obra de Vitruvio, escogerá recurrir a la iconografía que circulaba por la Europa del siglo XVI para su representación de las cariátides, aun debiendo acometer él mismo la labor de esculpir doncellas a modo de columnas en la tribuna del Louvre poco tiempo después. En lugar de producir un modelo de creación propia, para el que tenía cualidades indiscutibles, bebe directamente de la estampa de Raimondi para generar una ilustración con pocos gestos originales. Será Perrault, en el siglo XVII, el que rescate el modelo real esculpido por Goujon para incluirlo en su revolucionaria versión del Vitruvio. En un texto que pretende convertirse en principio de autoridad para la arquitectura francesa en los preludios de la Ilustración, Perrault decide acompañar el texto con arquitecturas reales coetáneas o relativamente recientes entre las que se cuenta la Tribuna de las Cariátides de Goujon a título de cumplido y justo reconocimiento.

\section{BIBLIOGRAFÍA}

BARBARO, Daniele; PALLADIO, Andrea (1556): I dieci libri dell'architettura di M. Vitruvio tradutti e commentate da Monsignor Barbaro. Francesco Marcolini. Venezia.

BustamanTE García, Agustín (1989): “Los grabados del Vitruvio complutense de 1582". Boletín del Seminario de Estudios de Arte y Arqueología. Tomo 55, pp. 273-288.

CAPORALI, Giovanni Battista (1536): Vitruvius, Architettura : con il svo cōmento et figure Vetruvio in volgar lingva raportato per M. Gianbatista Caporali de Pervgia. G. Bigazzini. Perugia.

Cellauro, Louis (1998): "Palladio e le illustrazioni delle edizioni del 1556 e del 1567". Saggi e Memorie di Storia dell'Arte. No. 22 (1998), pp. 57-128.

CesARIANO, Cesare (1521): Di Lucio Vitruvio Pollione de architectura libri decem. G. da Ponte. Como.

CiAPPONI, Lucia A. (1984): "Fra Giocondo da Verona and His Edition of Vitruvius". Journal of the Warburg and Courtauld Institutes. Vol. 47, pp. 72-90.

CHENeY, Liana (2006): The Homes of Giorgio Vasari. Peter Lang Publishing. New York. 
GIOCONDO, Giovanni Monsignori detto Fra (1511): M. Vitruvius per Iocundum solito castigatior factus cum figuris et tabula ut iam legi et inelligi possit. Ioannis de Tridino alias Tacuino. Venezia.

Homolle, Théophile (1917): “L'origine des Caryatides". Revue Archéologique. Cinquième Série, T. 5 (JANVIER-JUIN 1917), pp. 1-67.

KRUFT, Hanno-Walter (1994): A History of Architectural Theory from Vitruvius to the Present, Princeton University Press. New York.

MASSELLI, Giovanni (1832-1838): Le opere de Giorgio Vasari, pittore e architetto Aretino. David Passigli e socj. Firenze.

MARTIN, Jean; GoUjON, Jean (1547): Architecture, ou Art de Bien Bastir, de Marc Vitruve Pollion Autheur romain antique: mis de latin en Francoys. Iacques Gazeau. Paris.

PlOMMER, Hugh (1979): "Vitruvius and the Origin of Caryatids". The Journal of Hellenic Studies. Vol. 99, pp 97-102.

Perouse De Montclos, Jean-Marie (2007): “La tribune dite des Caryatides au Louvre. Essai d'interpretation". Revue de l'art. № 157, pp. 57-58.

Perrault, Claude (1673): Les dix libres d'Architecture de Vitruve- J.-B. Coignard. Paris.

REVEIL, Achille; Sulpis, Jean-Joseph; Audot, Louis-Eustache (1869): Oeuvre de Jean Goujon gravé d'après ses statues et ses bas-reliefs: accompagné d'un texte biographique et de tables explicatives des planches. A. Morel Editeur. Paris.

STEVENSON, Gregory (2001): Power and place: Temple and Identity in the Book of Revelation. De Gruyter. New York.

TOLOMEI, Claudio (1547): De le lettere di M. Claudio Tolomei Lib. Sette con una breue dichiarazione in fine di tutto l'ordin de l'ortografia di questa opera. Gabriel Giolito de Ferrari.Venecia.

VASARI, Giorgio (1568): Le Vite De' Piv Eccellenti Pittori, Scultori e Architettori. Appressso i Giunti. Fiorenza.

VASARI, Giorgio (1986): Le vite de' piú eccellenti pittori, scultori ed Architetti. Einaudi. Torino.

VICKERS, Michael (1985): "Persepolis, Vitruvius and the Erechteum Caryatids: The Iconografy of Medism and Servitude". Revue Archéologique. Nouvelle Série, Fasc. 1 (1985), pp. 3-28. 
Vitruvio Polion, Marco (c. 1486-1487): L. Victruvii Pollionis ad Cesarem Augustum de architectura. Edición de Giovanni Sulpizio. Roma.

Vitruvio Polión, Marco (1997): Los diez libros de Arquitectura. Alianza Forma. Madrid.

Vitruvio Pollione, Marco (1990): De Architectura. Edizioni Studio Tesi. Pordenone. 